\title{
CAVE Sanal Gerçeklik Teknolojisinin Üniversite-Sanayi İşbirliği Açısından Değerlendirilmesi ve Örnek bir Durum Çalışması
}

\author{
Cagatay Catal $^{1 *}$, Akhan Akbulut ${ }^{2}$ \\ ${ }^{1}$ Wageningen Üniversitesi, Bilişim Teknolojileri Grubu, 6706KN, Wageningen, Hollanda (ORCID: 0000-0003-0959-2930) \\ 2 İstanbul Kültür Üniversitesi, Mühendislik Fakültesi, Bilgisayar Mühendisliği Bölümü, 34156, İstanbul, Türkiye (ORCID: 0000-0001-9789-5012)
}

(İlk Geliş Tarihi 8 Ocak 2019 ve Kabul Tarihi 1 Mart 2019)

(DOI: $10.31590 /$ ejosat.510001)

ATIF/REFERENCE: Catal, C. \& Akbulut, A. (2019). CAVE Sanal Gerçeklik Teknolojisinin Üniversite-Sanayi İşbirliği Açısından Değerlendirilmesi ve Örnek bir Durum Çalışması. Avrupa Bilim ve Teknoloji Dergisi, (15), 61-69.

$\ddot{O} \mathbf{z}$

CAVE (CAVE Automatic Virtual Environment) sanal gerçeklik teknoloji altyapısı, yurt dışındaki üniversiteler ve araştırma kurumları tarafından, son dönemde farklı fonlarla kurulmaya başlanmış ancak Türkiye'de henüz bir üniversitede, yüksek yatırım maliyeti nedeniyle bu tür bir altyapı kurulamamıştır. Bu çalışmada bu tür bir merkezin kurulması durumunda hem üniversitelerin hem Türkiye'deki sanayinin ayrı ayrı kazanımları değerlendirilerek oluşabilecek sinerji ortaya konulmuştur. Bu merkezin belirli zaman dilimlerinde diğer eğitim kurumlarının kullanımına açılması, eğitime farklı bir boyut getirerek, anlaşılması güç olan kavramların, görsel ve üç boyutlu sanal gerçeklik ortamında kolaylıkla anlaşılması sağlanabilecektir. Eğitime sunulacak katkılarının yanı sıra, endüstriyel boyutta henüz ürünlerin ilk prototipleri yapılmadan, üç boyutlu modellerinin CAVE ortamına taşınarak ergonomi ve kullanıcı deneyim testlerinin yapılması mümkün olacaktır. Bu yönüyle, altyapının üzerinden ilgili kurum ve kuruluşlara ulaşılması, yeni AR-GE projelerinin geliştirilmesi sağlanabilecektir. Çalışmada sunulan örnek durum senaryosunda 130 metrekarelik bir alanda kurulabilecek bir CAVE altyapısı tanıtılmış olup gerekecek materyaller ve ekipmanlar aktarılmış, bu teknolojinin ayrıntılı değerlendirilmesi farklı boyutlarıyla ortaya konulmuştur. Bu tür bir merkez kurmak isteyen üniversiteler ve şirketler için Mantıksal Çerçeve Matrisi sunulmuştur.

Anahtar Kelimeler: Sanal gerçeklik, CAVE, Sanal ortam.

\section{The Evaluation of CAVE Virtual Reality Technology for the University-Industry Collaboration and a Case Study}

\begin{abstract}
The CAVE Automatic Virtual Environment (CAVE) virtual reality technology infrastructure has recently started to be built by different universities and research institutes using different funds, but according to our analysis, we did not encounter such an infrastructure in any university in Turkey due to the high investment costs. In this study, we present the benefits of universities and industry in Turkey and also provide synergistic artefacts. By opening this centre to the use of other educational institutions in certain time periods, it will present a different perspective for the education and make it easier to understand difficult concepts in a visual and 3-dimensional virtual reality environment. In addition to the contributions to the education, ergonomics analysis and user experience tests will be performed by moving $3 \mathrm{D}$ models to the CAVE environment before the first prototypes of products at the industrial scale are manufactured. It is possible to develop new R\&D projects to reach relevant institutions and organizations through this infrastructure. In the Case Study, a CAVE infrastructure to be installed in 130 square-meter area is introduced, necessary materials and equipment are introduced, and indepth evaluation of this technology is presented. We introduce a Logical Frame Matrix for the universities and companies.
\end{abstract}

*Sorumlu Yazar: Wageningen Üniversitesi, Bilişim Teknolojileri Grubu, 6706KN, Wageningen, Hollanda, cagatay.catal@wur.nl 
Keywords: Virtual Reality, CAVE, Virtual Environment.

\section{Giriş}

Sayısal modellerin sanal ortamda yaşayan hale getirilmesi ve bunların üç boyutlu görüntüler ve gözlükler ile kullanıcılara sunulmasını sağlayan interaktif görselleştirme sistemlerinin üniversitelerimizde hayata geçirilmesi kritik öneme sahiptir. Bu tür sistemlere CAVE (CAVE Automatic Virtual Environment) ismi verilmektedir. Yurt dışında birçok üniversite, sanayi kuruluşu ve araştırma merkezi, bu tür sistemleri son dönemde altyapı olarak kullanmaya başlamış ve bu yönde üniversite-sanayi işbirliğgini sağlamaya dönük önemli adımlar atmıştır. Bu ve benzeri sistemler sayesinde kullanıcılar, incelemek istedikleri modelleri CAVE sistemi içerisine alarak bunları gerçek dünyadaki gibi inceleyebilmektedir. Modellerin üç boyutlu görüntüleri ilgili sistem sayesinde oluşturulabilmekte, özel tasarlanmış gözlükler yardımıyla üç boyutlu olarak kullanıcıların kullanımına sunulabilmektedir. Aynı zamanda modeller üzerine, hareket takip cihazları sayesinde gerçek kullanıcıların pozisyon bilgileri, el hareketleri ve baş-boyun hareketleri aktarılarak sanal model içerisinde insan etkileşimi sağlanabilmektedir. ABD Ulusal Mühendislik Akademisinin (National Academy of Engineering) belirlemiş olduğu 21.yüzyılın büyük mühendislik hedeflerine bakıldığında bu hedeflerinden birisinin de Sanal Gerçekliğin geliştirilmesi olduğu görülmektedir [1]. Bu yönüyle bakıldığında bu tür altyapıların kurularak bu kapsamda projeler geliştirilmesi 21.yüzyılın büyük mühendislik hedeflerinden biriyle doğrudan ilişkilidir.

Sanayi kuruluşlarının; CAVE sanal gerçeklik sistemi için gerekli olan altyapı yatırımına, ekonomik olarak güçlerinin yetmediği durumda, üniversitelerimizde kurulacak olan bu merkezleri kullanması alternatif bir çözüm olacaktır. Bu tür projelerle disiplinler arası projeler yapılabileceği gibi farklı sektörlerle işbirliği tesis edilebilecektir. Ülkemizde henüz bahsi geçen nitelikte bir altyapı olmadığından, yurt dışında bu konularda çalışmak üzere gençlerimiz farklı ülkelere gitmek durumunda kalmayacaktır. Belediye ve kamu kurumlarının sanal gerçeklik ihtiyaçları, acil durum senaryoları gibi çok sayıda pratikte katkısı olabilecek uygulama sahalarını dikkate aldığımızda, bu tür altyapıların ülkemiz acısından önemli kazanımlar sağlayacağı görülmektedir. Gençler arasında bilimin sevdirilmesi, lise öğrencilerine belirli dönemlerde özel çalıştaylar düzenleyerek biyoloji, kimya, fizik gibi derslerin sanal gerçeklik ortamında farklı örneklerle gösterilmesi mümkün olabilecektir. Diğer önemli katkılarından bir diğeri de prototipleme maliyetlerinin düşürülmesidir. Ürünlerin ilk prototiplerinin üretilmeden, modellerin CAVE ortamında konumlandırılarak gerekli analizlerin ve ergonomi testlerinin yapılabilmesi mümkün olmaktadır. Sanal Gerçeklik konusunda uzman personel yetiştirilmesi, bu konularda çalışan akademisyenlerin belirli merkezler etrafında toplanması uzun vadede ülkeye fayda sağlayacak diğer hususlardır.

CAVE sistemlerinin alternatifi sistemler ise daha sınırlı destekler ve kazanımlar sunmaktadır. Örneğin başa monteli ekranlar (Head Mounted Display-HMD) ile sanal gerçekliğin sağlanmaya çalışıldığı Oculus Rift gibi cihazlar ile küçük çaplı uygulamalar geliştirilebilmektedir. Çok sayıda kısıtlaması olan bu tür HMD cihazlarla bile, ne yazık ki ülkemizde birçok bilgisayar mühendisliği öğrencisi eğitimleri sırasında tanışamamakta ve bu platformlar için uygulama geliştirmeden mezun olmaktadır. University of Illinois at Chicago gibi ABD merkezli üniversitelerde, mevcut durumda CAVE konusunda önemli projeler yürütülmektedir. Üniversiteler içerisindeki farklı bölümlerin katılımıyla disiplinler arası araştırmaların önünün açılması ve endüstri ihtiyacını karşılamaya yönelik projelerin geliştirilmesi bu tür merkezlerle mümkündür. Ülkemizde sadece Ford Otosan firması; bu tür bir CAVE sistemini geçtiğimiz yıllarda, kendi ürünlerinin ergonomi testleri için kurmayı hedeflemiş ve bu tür bir laboratuvarı kullanıma açmıștır. Yatırım maliyetinin yüksek oluşu nedeniyle tüm sanayi kuruluşlarının bu tür merkezler açması mümkün görünmemektedir. Bu ihtiyacı karşılayabilmek üzere, üniversitelerimizde bir CAVE merkezinin kurulması, bu konuda uzman personel yetiştirilmesi, lisans bitirme ve yüksek lisans tezleri yaptırılarak sonrasında disiplinler arası bir doktora programı olacak olan Simulasyon ve Modelleme doktora programlarının açılması, bu konuda Avrupa Birliği proje çağrılarına katılarak yeni işbirliklerinin tesis edilmesi diğer faydalar olarak sıralanabilir.

Sonraki bölümlerde CAVE teknolojisi konusunda genel bilgiler ve ilişkili çalışmalar sunulmaktadır. Bölüm 5 'de üniversite ve sanayi kazanımları sunularak bu tür bir merkez kurmak isteyen organizasyonlar için ilgili Mantıksal Çerçeve Matrisi ortaya konulmuştur. $\mathrm{Bu}$ matrisler proje planlama izleme ve değerlendirme için değerli araçlardandır. Bölüm 6'de bu tür merkez kurmak isteyenler için örnek çizimlerle sistemin genel görüntüsü sunulmakta, 130 metrekarelik bir alan için yapılan tasarımla resmedilmektedir. Bölüm 7'de sonuçlar ortaya konulmaktadır.

\section{Genel Bilgi ve İlişkili Çalışmalar}

CAVE platformları; yeni nesil tiyatral sanallaştırma uygulamalarının görselleştirilmesinde rol almaktadır. Kullanıcıların içerisine girebileceği sanal gerçeklik tecrübeleri için bünyesinde yüksek çözünürlüklü projeksiyon, perde ve takip kameraları kullanılmaktadır. CAVE platformlarının tercih edilme nedenleri aşağıda sıralanmaktadır:

- Yüksek çözünürlüklü renkli görüntüleri geometrik bozulma olmadan çevresel gözlemleyebilme,

- Baş hareketi kaynaklı hataların daha az hassasiyetle değerlendirilebilmesi,

- Çoklu kullanıcılı oturumlarda yapay ortamların analiz ve öğretimini sağlaması,

- Bilimsel verilerin görsel sunumları ile anlamlarının zenginleştirilmesinin sağlanması,

- Kendisine bağlanabilen süper bilgisayarlar ile paralel veri işleyerek yüksek performanslı gösterimle yapılabilmesidir.

CAVE teknolojisi ilk kez University of Illinois at Chicago (UIC) üniversitesinde ortaya konulmuş bir fikir olup, 1992 yllında SIGGRAPH konferansında sunulmuştur [2]. UIC üniversitesi, geliştirmekte olduğu CAVE teknolojisinin satışını şu anda MechDyne firması üzerinden gerçekleştirmektedir. CAVE2 ürününün [3] bedeli yaklaşık olarak 2 milyon dolar olduğundan, LCD bazlı olan CAVE2 
ürünü yerine projeksiyon bazlı CAVE sistemlerinin maliyet-etkin olduğu değerlendirilmektedir. Bu nedenle, maliyet-etkin olmas1 istendiği durumda görselleştirme kalitesinden bir nebze ödün vererek, projeksiyon bazlı sistemler referans alınarak tasarımların yapılması mümkün görünmektedir. Genellikle bu tür projektör bazlı yaklaşımlar tercih edilmektedir.

Ürün tasarım doğrulaması, şehir planlama, maden sahaları, tarihsel mekanların üç boyutlu görüntülenmesi, tıbbi araştırma, sanal eğitim, pazarlama ve ürün tanıtım gibi cok çeşitli uygulama alanları bulunmaktadır. 4 duvar yansımalı gerçek zamanlı sanal gerçeklik sistemleri sayesinde, mühendislik tasarımlarının doğrulaması mümkün olmakta ve bu analizlerin haricinde eğitim amaçlı da sistemler kullanılabilmektedir. Havacılık ve savunma sektöründe kokpit personelinin eğitimi, maliyet açısından daha ucuz olabilmektedir. Yurt dışında CAVE teknolojileri konusunda ön plana çıkan firmalar VisBox [4] ve MechDyne [5] firmaları olup, yurt içinde infoTRON [6] firması bu konuda çalışmaktadırlar. CAVE sistemi için genellikle, 4 adet aktif stereo projektör, 4 adet ön yüzey aynası, stereo emitörler, 10 kadar stereo shutter gözlük tedarik edilerek sistemler kurulabilmektedir. Yan duvarlar, karşı duvar ve yer yüzeyine görüntülerin aktarılabilmesi için 4 adet özel projektöre ihtiyaç bulunmaktadır. Aynı zamanda, gerçek zamanda eğitmeni takip edebilmek için genellikle 4 kameralı optik takip sistemi tedarik edilmesi gerekmektedir. Modellerle etkileşebilmek için ise wand ismi verilen işaretçi/fare cihazları kullanılabilmektedir. Bu tür optik takip sistemlerinin performansı yüksek olduğundan CAVE sistemlerinde tercih edilmektedirler. CAVE sisteminde sanal gerçeklik hissini sağlayabilmek üzere 5.1 çevresel ses sistemi ayrıca kurulabilmektedir. Ürün tedarikleri yurt dışından yapıldığı durumda, tedarik süreleri zaman almakta ve bu sürede, gerekli yazılım geliştirme ortamları ve geliştirme teknolojileri konusunda grupların bilgi edinmesi faydalı olmaktadır. Ürünler tedarik edildikten sonra, mekanik ve donanımsal kurulumlar gerçekleştirilmekte, yazılımlar bu platformların üzerine kurulmakta, platformun kalibrasyonunun yapılması amacıyla farklı yazılımlardan yararlanılmaktadır. Bunların ardından, ilgili eğitimler gerçekleştirilerek sistemin kullanıma açılması sağlanmaktadır.

Muhanna [7] derleme çalışmasında, farklı sanal gerçeklik sistemlerini CAVE ile birlikte karşılaştırmış, sanal gerçeklik sistemleri için bir taksonomi önermiştir. Ip ve arkadaşları [8], otizm spektrum bozukluğu bulunan yaşları 6 ile 12 arasında olan 94 çocuğun, duygusal ve sosyal yeteneklerini geliştirmek üzere sanal gerçeklik ortamında (yarım CAVE olarak adlandırabileceğimiz bir ortam) 6 öğrenme senaryosu üzerinde çalışmış ve olumlu katkılarının bulunduğunu raporlamıştır. Fabrika ve arkadaşları [9], CAVE içerisinde bir ormanın görselleştirmesini yapmış ve sanal ortamla etkileşimde olan bir seyreltme uzmanının eğitimini sağlamaya çalışmışırı. Fernández ve Alonso [10], gemi inşası alanında CAVE teknolojisinin sağlayacağı yararları ayrıntılandırmışıtır. Limniou ve arkadaşları [11], kimya eğitiminde 2 boyutlu masaüstü simülasyon uygulamalarının kullanımıyla CAVE teknolojisinin uygulandığı durumu karşılaşıırmış ve CAVE teknolojisinin öğrenciler arasında daha olumlu etkiler oluşturdugunu raporlamıştır. Sinitski ve arkadaşları [12], Kanada Silahlı Kuvvetleri personelinin deneylerde olduğu bir çalışmada, CAVE gibi simülasyon ortamlarının simülatör kaynaklı rahatsızlıklara (örneğin, baş dönmesi) yol açıp açmadığını araştırmıştır.

\section{CAVE Teknolojisi}

Birçok CAVE uygulamasında, yüzeyler (duvarlar, zemin ve tavan) büyük boyutlu ekran ekipmanlarıyla donatılır. CAVE'ler için kullanıcının fiziksel yönelimini ve hareketlerini takip etmesi, bunlara cevap vermesini sağlayan araçlar kullanılmaktadır. Tercih edilen yüzey sayısına bağlı olarak kurulum maliyeti değişkenlik göstermektedir. Örneğin tek bir yüzeyin kullanıldığı Wall sistemleri en temel form olarak değerlendirilmektedir. Yüzey sayısının arttırıldığı konfigürasyonlarda sanal gerçeklik hissi de beraberinde artmaktadır. Bir CAVE sistemi temel olarak aşağıdaki bileşenlerden oluşur [13]:

- Görüntü Sistemi: CAVE video sistemi, yüzeylerde pencere sunumu kullanarak, sanal gerçeklik ortamları yaratmaktadır. Kullanılan gözlükler üzerindeki pozisyon sensörlerinin ölçümleri vasıtasıyla, doğru perspektif açısı hesaplanmaktadır. Gözlük camları, her bir göze farklı görüntülerin gösterilmesini sağlayarak üç boyut hissi sağlar.

- Ses Sistemi: Genel olarak, üç boyutlu görsellerin temsiline uygun ses sistemlerinin kullanımı için geliştirilmiş projeler (Creative EAX gibi) tercih edilmektedir. Bu sistemler; CAVE ortamı için çok kanallı mekansal ses çözümleri sunarak, CAVE içinde birden fazla kullanıcıya görsel ve işitsel kullanım deneyimi sağlamaktadır.

- Takip Sistemi: CAVE’ler içerisinde farklı takip sistemleri kullanılabilmektedir. Kameralar ve görüntü işleme yöntemleri kullanılarak gözlük üzerindeki işaretçilerin yeri tespit edilerek kullanıcı hareketleri takip edilebilmektedir. Bu çözüm için ARToolkit [14] açık kaynak kodlu platformun kullanımı yaygındır. İdeal çözüm denilebilecek çözüm ise en yüksek doğruluk sunabilen, birden çok bakış açısı kullanan aktif işaretleyicilerle optik izleme sistemlerinin kullanılmasıdır.

- Grafik Motoru: CAVE platformları için 3D grafik yazılımı oldukça sınırlıdır. Birçok proje, standart oyun motorlarını (Unity3D gibi) bir CAVE kurulumunda kullanabilmek üzere uyarlamıştır [15]. CAVE'e özel geliştirilmiş en bilindik grafik motoru CAVELib'dir.

- Stereografik Sahneleme Sistemi: Stereografik görüntülemenin temel gereksinimi olan iki görüntü ve bunların aynı anda görüntülenmesi, sağ göz ve sol göz için hesaplanarak sunulmaktadır. Yüksek yenileme hızına sahip CRT projektörler kullanılarak 3 boyut hissi verilmektedir. Sahneleme için yüksek performanslı grafik kartları kullanılmaktadır. Çok sayıda kullanıcı için sahneleme gecikmelere sebebiyet verebilir. Sahneleme verecek sistemin gereksinimleri planlanırken, kullanıcı sayısına bağlı olarak grafik kartlarının çoğaltılması gerekebilmektedir.

\section{CAVE ve Başa Takılan Ekranlar}

Günümüzde sanal gerçeklik denilince ilk akla gelen ürünler başa monteli ekranlardır (Head Mounted Display-HMD). En bilindik ürünler arasinda Oculus Rift [16], Microsoft HoloLens [17], HTC Vive [18] ve Samsung Gear VR [19] sayılabilir. CAVE sistemlerinin başa takılan ekranlardan farkları, son kullanıcılar tarafindan henüz bilinmemektedir. Bu bölümde CAVE ve HMD cihazlar arasındaki 
farklılıklara değinilecek ve HMD ürünler arasındaki öncü sayılabilecek Oculus Rift ile kıyaslama yapılacaktır. Bir HMD sistemi, etkileşimli kontrol cihazları ve stere ekran ile gerçek zamanlı kafa perspektifi esaslı görüntü sağlar. CAVE sistemlerinin geliştirilmesindeki temel amaç, bu ürünlerin kısıtlamalarından kurtulmaktır. Özellikle geniş açılardan bakışın gerektiği mühendislik uygulamalarında, CAVE sistemleri prototip geliştirmede önemli rol oynamaktadır. Bir diğer temel fark, aynı oturumda birden fazla kullanıcının sanal gerçeklikle etkileşime girebilmesidir. Sanal Gerçeklik kullanımı sırasında gerçek dünyadan izole olma, beyin üzerinde olumsuz etkiler yapmakta ve kullanıcılarda baş dönmesi ve bulantı gibi istenmeyen sonuçlar doğurmaktadır. CAVE sistemlerinde kullanıcılar, HMD ürünlerindekinin aksine, gerçek dünyadan tam anlamıyla izole edilmezler ve bunun sonucu olarak daha uzun süreli kullanımlar mümkün olabilmektedir. Ayrıca, kullanıcı hareketlerini izleyen donanımın çokluğu sayesinde, sanal gerçeklik ile olan etkileşim daha yoğundur ve takip hataları daha azdır. Tablo 1'de Oculus Rift ile yapılan kıyaslama sunulmaktadır.

Tablo 1. CAVE ve HMD Klyaslamasl.

\begin{tabular}{lll}
\hline Kıyaslama Kriteri & \multicolumn{1}{c}{ CAVE } & \multicolumn{1}{c}{ Oculus Rift } \\
\hline Kullanıcı Sayısı & 1 aktif 15 izleyici kişiye kadar & 1 aktif kişi \\
Çözünürlük & $\sim 3-10$ MP (tek göz için) & $\sim 1 \mathrm{MP}$ (tek göz için) \\
Bakış Açısı & $170^{\circ}$ & $100^{\circ}$ \\
Hareket Sınırlaması & Yok, Kablosuz Cihazlar & Sınırlı, Kablolu Cihaz \\
Kullanım Rahatlığı & Uzak ve geniş ekranlarda daha uzun & Yakın görüntünün uzun süreli \\
& süreli kullanım imkanı & kullanımına bağlı rahatsızlıklar \\
Kullanıcı Temsili & Kullanıcının Gerçek Vücudu & Sanal Vücut \\
Konfor & işaretçiler ve gözlük ile rahat & Ağı̈ gözlük yüzünden uzun \\
Takip Hassasiyeti & Kusursuz & süreli kullanımda yorucu \\
Kurulum Maliyeti & Çok Pahalı & Yüksek \\
\hline
\end{tabular}

Her iki sistem kıyaslandığında; Oculus Rift'in taşınabilir, kurulumunun kolay ve düşük maliyetli olması ile son kullanıcılar için önemli bir çözüm olduğu görülmektedir. Özellikle oyun sektörünün bu ve benzeri cihazlar ile kullanımı yaygınlaşmaktadır. Öte yandan; CAVE sistemleri daha yüksek çözünürlük, daha geniş kullanım açısı, gerçek dünyadan kopmama, milimetrik hassasiyet ile kullanıcı takibi yapabilmesi ve çok sayıda kullanıının aynı anda sistemi kullanabiliyor olması nedenleriyle mühendislik uygulamalarında daha yüksek histe sanal gerçeklik sunmaktadır. Olumsuz yanları ise kurulum maliyetinin daha yüksek ve işletme giderlerinin daha fazla olmasıdır.

\section{5. Üniversite, Sanayi ve Üniversite-Sanayi İş Birliği İçin Değerlendirmeler}

\subsection{Genel Değerlendirmeler}

CAVE altyapılarının üniversitelerde veya şirketlerde kurulmasının, eğitim-öğretim ve sanayi boyutlarında iki farklı hedef grubu mevcuttur. Üniversiteler bünyesinde birçok bölümde; anlaşılması güç ve teorik kavramların görselleştirilmesi sayesinde bu konuların daha kolay algılanması ve akılda kalması mümkün olabilmektedir. Örneğin, çok sayıda sistem ve alt sistemden oluşan bir araç motorunun çalışma prensiplerinin daha rahat açıklanabilmesi ve öğrenilebilmesi için, CAVE üzerinde üç boyutlu bir model kurgulanarak, farklı kesitlerin görselleştirilip tüm parçaların detaylarıyla birlikte gösterilmesi mümkün olabilmektedir. Başka bir örnek olarak; MARS yüzeyinin fotoğraflarını kullanıp o ortamda geziyor hissine kapılmak ve ortamı keşfetmeye çalışmak, oldukça heyecan verici bir duygudur. Fizik bölümlerinde verilen Astronomi derslerinde bu tür görsel modellerin, benzer şekilde Moleküler Biyoloji ve Genetik Bölümlerinde farklı protein yapılarının görselleştirilerek öğrencilere sunulması eğitime yeni bir boyut getirebilecektir. Ayrıca, liselerde öğrenim gören öğrencilerin, farklı çalıştaylarla bu imkanlardan yararlanması gençlerin ufkunu açarak bilimi sevmelerini sağlayacaktır. Bu tür merkezler kurularak, bölgeler arasındaki gelişmişlik farklılığı azaltılabilecek ve bu tür altyapılar ülkemiz gençlerinin kullanımına sunulmuş olacaktır.

Benzer merkezler kurulduktan sonra, izleyen dönemlerde sanayi kuruluşlarının ihtiyaçlarını karşılamak ve kamu kurumları / belediyelerle birlikte ortak projeler üretebilmek için imkanlar oluşabilmektedir. Mühendislik kapsamında; hava kirliliği emisyon çalışmaları, aerodinamik analizleri, hızlı ürün prototipleme, araç içi ve dışı tasarımı gibi alanlarda çalışılabilmektedir. Mimari kapsamında; şehir planlama, iç tasarım, bina tasarımı yapılabilmekte olup bu sayede bina inşa edilmeden önce, binanın içerisinde gezilmesi, bina ergonomisinin değerlendirilmesi, günün çeşitli saatlerinde bina üzerinde güneşin etkisinin incelenmesi, depreme dayanıklılığın belirlenmesi mümkün olabilmektedir. Tıp alanında; sanal kadavralar kullanılarak genç doktorların deneyim kazanması, laparoskopik cerrahide çalışacak olan doktorların eğitimi, insan anatomisinin görselleştirilmesi, psikolojik terapinin sağlanması, moleküler biyoloji eğitimi verilmesi gibi çok sayıda uygulama gerçekleştirilebilmektedir. Bu tür bir merkezin kurulmasıyla birlikte aşağıdaki sonuçlar elde edilebilecektir:

- Disiplinler arası projeler: Üniversitelerin Bilgisayar Mühendisliği, İnşaat Mühendisliği, Elektronik Mühendisliği, Moleküler Biyoloji ve Genetik, Mimarlık ve Fizik gibi Bölümlerinin Öğretim Üyelerinin disiplinler arası projeler geliştirebilmesine katkı sağlamaktadır. Bu tarz disiplinler arası projelerin geliştirilmesi, sanayi kuruluşları ile ortak projeler tasarlanması ve eğitimde farklılık yaratılması mümkündür. Üniversitemiz ve diğer sanayi kuruluşları / kamu kuruluşları ile artık çok daha kolay ortak projeler geliştirilebilecek ve işbirliği üst seviyelere taşınmış olabilecektir. Belediyeler ve kamu kurumları gibi ülkemizin önemli kurumları ile işbirliğine gidilerek, acil durum tatbikatları ve felaket senaryolarının uygulanması, mimari tasarımların analizi, karmaşı cihaz ve sistemleri kullanacak olan teknik personelin eğitimi gibi birçok konuda uygulamalar geliştirilebilmesi söz konusudur. Ülkemizde 
arzulanan üniversite-sanayi işbirliğinin sağlanması için doğrudan sanayi kuruluşlarının ihtiyacına dönük olarak modelleme / simülasyon / görselleştirme çalışmalarının CAVE üzerinde yapılması mümkündür. Ürünlerin ilk prototipleri çıkmadan önce, sanal gerçeklik ortamında, 3 boyutlu modeller kullanılarak ürün tasarımının analiz edilmesi ve üretim öncesi ergonomi testlerinin gerçekleştirilmesi mümkündür.

- Uzman yetiştirilmesi: Sanal Gerçeklik konusunda uzman yetiştirilmesi, bu konuda teknolojinin geldiği en son nokta olan CAVE sistemi üzerinde doğrudan çalışarak bilgi ve becerilerinin arttırılması, bu kapsamda yeterli altyapı ülkemizde henüz olmadığı için yurt dışında doktora yapmak zorunda kalan öğrencilerimizin yeniden ülkemiz altyapısına yönlendirilmesi mümkün olmaktadır. Bilgisayar Mühendisliği öğrencilerinin sanal gerçeklik teknolojileri konusunda doğrudan uygulama geliştirip içerisinde gezebilecekleri bir platform ortaya konulmuş olacaktır. Projektörler, aynalar, stereo gözlükler, işaretçi, gerçek zamanlı takip kameraları, ses sistemleri ve ana bilgisayarıyla bütünleşik bir CAVE ortamı inşa edilerek, kurulumların yapılması ve kalibrasyonlarının tamamlanması neticesinde üç boyutlu modeller ve gerekli yazılımlarla birlikte kullanıma açılabilecektir. Sanal Gerçekliğe hakim, simülasyon ve modelleme alanlarında askeri ve sivil uygulama geliştirebilen uzmanlar yetiştirilebilecektir. CAVE sistemi faal duruma getirildikten sonra, bu sisteme içerik sağlayabilecek, gerekli altyapı yazılımlarını ve yazılım geliştirme ortamlarını bilen, bu teknolojilerde uygulama geliştirebilen uzman personeller yetiştirilebilecektir.

- Bilimin sevdirilmesi: Lise öğrencilerine belirli dönemlerde yapılacak çalıştaylar sayesinde, gençlerimiz arasında bilimin sevdirilmesi, bu alanda çalışacak gençlerimizin sayısının arttırılması söz konusudur. Toplumda ve gençler arasında bilimin sevdirilmesi ve merak uyandırılması sağlanmış olacaktır.

- Eğitimde sanal gerçeklik: Eğitimde sanal gerçekliğin doğrudan uygulaması gerçekleş̧irilerek, farklı bir model oluşturulabilecek ve ülkemiz genelinde yaygınlaştırılabilmesi için çalıştay ve bilgilendirme toplantıları düzenlenerek üst seviye bilgi paylaşımı sağlanabilecektir. Altyapı açısından diğer üniversitelerle benzer altyapıya sahip olarak, rekabet edebilirlik ve ortak proje geliştirilebilirlik açısından büyük bir ivme sağlanabilecektir. Başa monteli ekranlar ile sanal gerçekliğin sağlanmaya çalışıldığı Oculus Rift gibi cihazların neden olduğu kısıtlamaların ortadan kaldırılarak, eğitmen ve öğrenci rolünde birden fazla kişinin sanal gerçeklik deneyimini aynı anda paylaşmasına imkan tanımaktadır.

- Uzay / enerji gibi yeni alanlar için yeni projeler: Sadece güçlü olduğumuz; otomotiv / savunma sanayi / makine-imalat / inşaat / bilgi ve iletişim teknolojileri alanlarında değil, ülke çapında ivme kazanmamız gereken diğer alanlar olan uzay / enerji alanları için de yeni projelerle birlikte güç kazanılabilecektir. CAVE teknolojisinin savunma ve enerji alanında çok sayıda uygulaması yapilabilecektir.

$\mathrm{Bu}$ tür altyapılardan uzun vadede yarar sağlayacak olanlar, ülkemizin Bilgisayar Mühendisliği bölümleri ve mezunları, başta otomotiv sektörü ve savunma sanayi olmak üzere birçok sanayi kuruluşu ve önemli bazı kamu kurumları olacaktır. Kurulacak bu tür bir AR-GE merkezinin vizyonlarından birisi de, bulunduğu il sınırları içerisinde sanal gerçeklik konusunda çalışma yapacak olan bölüm ve öğretim üyelerinin sayısını arttırmak, bu alanda çalıştaylar ve konferanslar düzenlemek olabilecektir. Avrupa Birliği'nin Horizon2020 projelerinde CAVE gibi altyapılara sahip olan üniversiteler ve kuruluşların çok sayıda projede kendisine yer bulabilmesi söz konusu olduğundan, uzun vadede Avrupa Birliği fonlarından ülkemize daha fazla desteğin kaydırılabilmesinin önü açılabilecektir. Bilimi seven gençler yetiştirerek, uzun vadede bilimin toplumun algısındaki değeri daha da artacak, bilgi ve teknoloji odaklı üretimler gerçekleştirilebilecektir. Karmaşık üç boyutlu modellerin ve yapıların, bu tür sanal gerçeklik sistemleriyle incelenmesi, hem ülkemizdeki sanayi firmaları hem de eğitim kurumları açısından, mevcut sınırları ve sınırlandırmaları aşarak, ilk bakışta mümkün görünmeyen analizleri, eğitimleri ve bilimsel araştırmaları mümkün kılabilecektir.

\subsection{Sürdürülebilirlik}

Bu tür bir merkezin kurulmasıyla birlikte, sanal gerçeklik ve özelinde CAVE teknolojisi konusunda uzman personeller yetiştirilmiş ve gerekli altyapı kurulmuş olacağından, yeni projelerin Avrupa Birliği fonları, EUREKA ve diğer TÜBİTAK destekleriyle, şirketlerin doğrudan sunacağı finansal desteklerle geliştirilmesi mümkün olacaktır. Sadece yeni projeler çerçevesinde finansal model kurgulanmak durumunda kalınmayacak olup şirketin kurum içi eğitimine dönük olarak da bu sistemler adapte edilebilecektir. Aynı ortamın farklı düzenlemeler ve gerekli yazılımlarla bir simülatör platformuna dönüştürülmesi mümkündür. Örneğin vinç operatörlerinin veya diğer teknik bilgi gerektiren alanlarda çok sayıda eğitimin hem sanal gerçeklik hem de üç boyutlu görselleştirme imkânlarıyla birlikte gerçekleştirilmesi sağlanabilir. Bu tür bir merkezi bünyesine katmayı planlayan üniversiteler ve şirketler, kurumsal açıdan stratejilerini şekillendirebilecek, belirledikleri alanlarda kolaylıkla proje yapabilir duruma gelecektir. Merkezi bu bağlamda kurumsal yapının uygun birimine dahil eden organizasyonlar, sürecin sonunda daha fazla proje üretir konuma gelecektir.

ABD'de Ulusal Mühendislik Akademisi, tüm dünyadan uzmanlara danışarak, 21. Yüzyllda mühendislik disiplinlerinin önündeki 14 zorlu alanı belirlemiş ve bunları 'Grand Challenges for Engineering' başlı̆̆ ile yayınlamıştır. Bu 14 kritik ve zorlu alanlardan birisi de Sanal Gerçekliğin geliştirilmesidir. Bilgisayarda oluşturulan sanal ortamlar eğitimden eğlenceye, endüstriyel tasarımdan tıbbi tedaviye kadar, her alanda etkinliği ve verimi artırmak amacıyla aktif olarak kullanılmaktadır. Günümüzde gelişen teknoloji ile sanal gerçeklik sadece bir görsel yanılsama olmaktan çıkmış, bulunulan yerde olduğu duygusunu verecek ses, dokunma, hareket duygusuyla zenginleştirilmiş durumdadır. Bu konuda ülkemizde yapılacak olan çalışmalar, sanal gerçeklik çalışmalarının önünü açacak, sanayi kuruluşlarının bu alandaki zenginlikleri keşfetmesini sağlayacaktır. Toplum ve gençlerimiz tarafından bilimin hayatın her alanında önemli katma değerler sağladığı daha fazla görülecek, yapılacak çalıştaylarda fen bilimleri ve mühendislik, gençlerin seveceği ve devamında projeler üretebileceği bir boyuta taşınacaktır. Bu tür bir sistemde erken dönemde bulunmuş bir gencin, devamında teknoloji ve fen bilimleri odaklı alanlarda kariyer yapması doğal bir sonuç olacaktır. Bu yönüyle genç nüfusumuzun gerek bu tür çalıştaylar gerekse yazılı ve görsel medya aracılı̆̆ıla kurulacak merkez konusunda bilgi sahibi olması mümkün görünmektedir. 
Tablo 2. Mantıksal Çerçeve Matrisi.

\begin{tabular}{|c|c|c|c|c|}
\hline & Proje Mantığ & $\begin{array}{c}\text { Objektif Olarak } \\
\text { Doğrulanabilir Başarı } \\
\text { Göstergeleri }\end{array}$ & $\begin{array}{c}\text { Doğrulama } \\
\text { Kaynakları ve } \\
\text { Araçları } \\
\end{array}$ & Varsayımlar \\
\hline Genel Amaç & $\begin{array}{l}\text { Disiplinler arası çalışmaların yapılabileceği bir } \\
\text { AR-GE merkezi kurmak }\end{array}$ & $\begin{array}{l}\text { İlgili ekipmanlar ve } \\
\text { yazılımların mevcut olduğu } \\
\text { fiziksel ortamın } \\
\text { oluşturulmuş olması }\end{array}$ & Yerinde ziyaret & $\begin{array}{l}\text { Yeterli finansal } \\
\text { kaynak bulunmas1 } \\
\text { veya fonlanması }\end{array}$ \\
\hline $\begin{array}{r}\text { Özel } \\
\text { Amaçlar }\end{array}$ & $\begin{array}{l}\text { Sayısal verilerin ya da modellerin sanal } \\
\text { ortamda yaşayan hale getirilmesi, üç boyutlu } \\
\text { görüntüler ve gözlükler ile kullanıcılara } \\
\text { sunulması, sanal modeller üzerinde insan } \\
\text { hareketlerinin hareket takip araçları sayesinde } \\
\text { sisteme aktarılmasını sağlayan etkileşimli } \\
\text { görselleştirme sisteminin hayata geçirilmesi }\end{array}$ & $\begin{array}{l}\text { Örnek bir üç boyutlu } \\
\text { modelin CAVE sisteminde } \\
\text { yüklenerek eğitmenin } \\
\text { hareketlerini takip kamera } \\
\text { sistemleri algılayarak } \\
\text { modelle etkileşime geçmesi } \\
\text { sağlanmall, katılımcıların } \\
\text { bu modelleri görebilmesi }\end{array}$ & $\begin{array}{l}\text { Kullanıcı } \\
\text { deneyiminin } \\
\text { video görüntüsü }\end{array}$ & $\begin{array}{l}\text { Sistem } \\
\text { kalibrasyonunda } \\
\text { problem olması } \\
\text { durumunda sanal } \\
\text { ortamdaki } \\
\text { deneyimin istenilen } \\
\text { düzeyde } \\
\text { sağlanamama riski }\end{array}$ \\
\hline $\begin{array}{l}\text { Beklenen } \\
\text { Sonuçlar }\end{array}$ & $\begin{array}{l}4 \text { ekranı olan, kenar birleşimlerinde hatasız } \\
\text { görüntü veren, 1/1 ölçekte gösterim sunan, hem } \\
\text { 3D stereo hem de 2D mono sunabilen, DLP } \\
\text { (Digital Light Processing) teknolojisi sayesinde } \\
\text { tepki hızı ve renk derinliği benzersiz olan, } \\
\text { kamera sistemi, takip sistemi ve kızılötesi } \\
\text { teknolojisiyle çalışan, ekranı esnek } \\
\text { malzemeden imal edilen bir CAVE sistemi } \\
\text { oluşturmak, aynı ortamı kullanabilen farklı } \\
\text { yazılımlar bulundurmak }\end{array}$ & $\begin{array}{lcr}\text { Karmaşık } & \text { bir } & \text { sistemin } \\
\text { modeli } & 1 / 1 & \text { ölçekte } \\
\text { modellenip } & \text { sisteme } \\
\text { yüklenerek } & \text { renk ve tepki } \\
\text { hızının incelenebilmesi, } \\
\text { ekranların modeli hatasız } \\
\text { yansitabilmesi }\end{array}$ & $\begin{array}{l}\text { Ekran üzerindeki } \\
\text { model }\end{array}$ & $\begin{array}{l}\text { Tüm ekipman ve } \\
\text { yazılımların } \\
\text { zamanında ilgili } \\
\text { merkeze getirilmesi }\end{array}$ \\
\hline Faaliyetler & $\begin{array}{l}\text { Sistem gereksinim analizi gerçekleştirildikten } \\
\text { sonra, sistem donanım ve yazılım tasarımı } \\
\text { gerçekleştirilecek, kurulum ve kalibrasyonun } \\
\text { ardından sistem faal hale getirilecektir. Yazılım } \\
\text { geliştirme ortamları hazırlanacaktır. }\end{array}$ & $\begin{array}{l}4 \text { adet projektör, görüntü } \\
\text { birleştirme ekipmanları, } \\
\text { ekran ve izleme sistemleri, } \\
\text { bilgisayar donanımı ve ağ } \\
\text { birimlerinin mevcut olması }\end{array}$ & $\begin{array}{l}\text { Aylik ilerleme } \\
\text { raporlama ve } \\
\text { sistem kurulum } \\
\text { aşamalarının } \\
\text { gösterimsel } \\
\text { çıktıları }\end{array}$ & $\begin{array}{l}\text { Donanımların } \\
\text { çoğunun yurt } \\
\text { dişından tedarik } \\
\text { edilmesine bağl1 } \\
\text { gecikme ve ithalat } \\
\text { riski }\end{array}$ \\
\hline On noșui & 130 metrekarelik alan & & & \\
\hline
\end{tabular}

\section{6. Örnek Durum Çalışması}

Durum çalısmasında; CAVE sistemi için 4 adet aktif stereo projektör, 4 adet ön yüzey aynası, stereo emitörler, 10 adet stereo shutter gözlük tedarik edilerek sistemin kurulması planlanmıştır. Yan duvarlar, karşı duvar ve yer yüzeyine görüntülerin aktarılabilmesi için 4 adet özel projektöre ihtiyaç bulunmaktadır. Aynı zamanda, gerçek zamanda eğitmeni takip edebilmek için 4 kameralı optik takip sistemi tedarik edilmesi gereklidir. Modellerle etkileşebilmek için 1 adet wand ismi verilen cihaz kullanılması gerekir. Bu tür optik takip sistemlerinin performansı çok yüksek olduğundan, CAVE sistemlerinde kullanılmaktadırlar. CAVE sisteminde sanal gerçeklik hissini sağlayabilmek üzere 5.1 çevresel ses sistemi gereklidir. Yazılımların tedarik edilmesiyle birlikte, CAVE sistemi üzerinde çalışma yapmak mümkün olacaktır. Özetle, ürünler tedarik edildikten sonra, CAVE için tahsis edilen 130 metrekarelik alanda, mekanik ve donanımsal kurulumlar gerçekleştirilerek, yazılımlar bu platformların üzerine kurulabilecek, platformun kalibrasyonunun yapılabilmesi için önceden geliştirilmiş VMD (Visual Molecular Dynamics) gibi yazılımlardan yararlanılabilecektir. Daha sonra, sistemin eğitim ve sanayide uygulama alanları ortaya konularak, bu tür bir yatırım projesinin devamı için yeni projelerin temelleri oluşturulabilecektir.

Şekil 1'de 4 kullanım yüzeyi bulunan (3 duvar ve zemin) sistemin tasarımı sunulmaktadır. Her yüzey için bir yansıtma ekipmanı doğrudan projeksiyon yapabilecek şekilde konumlandırılmıştır. 


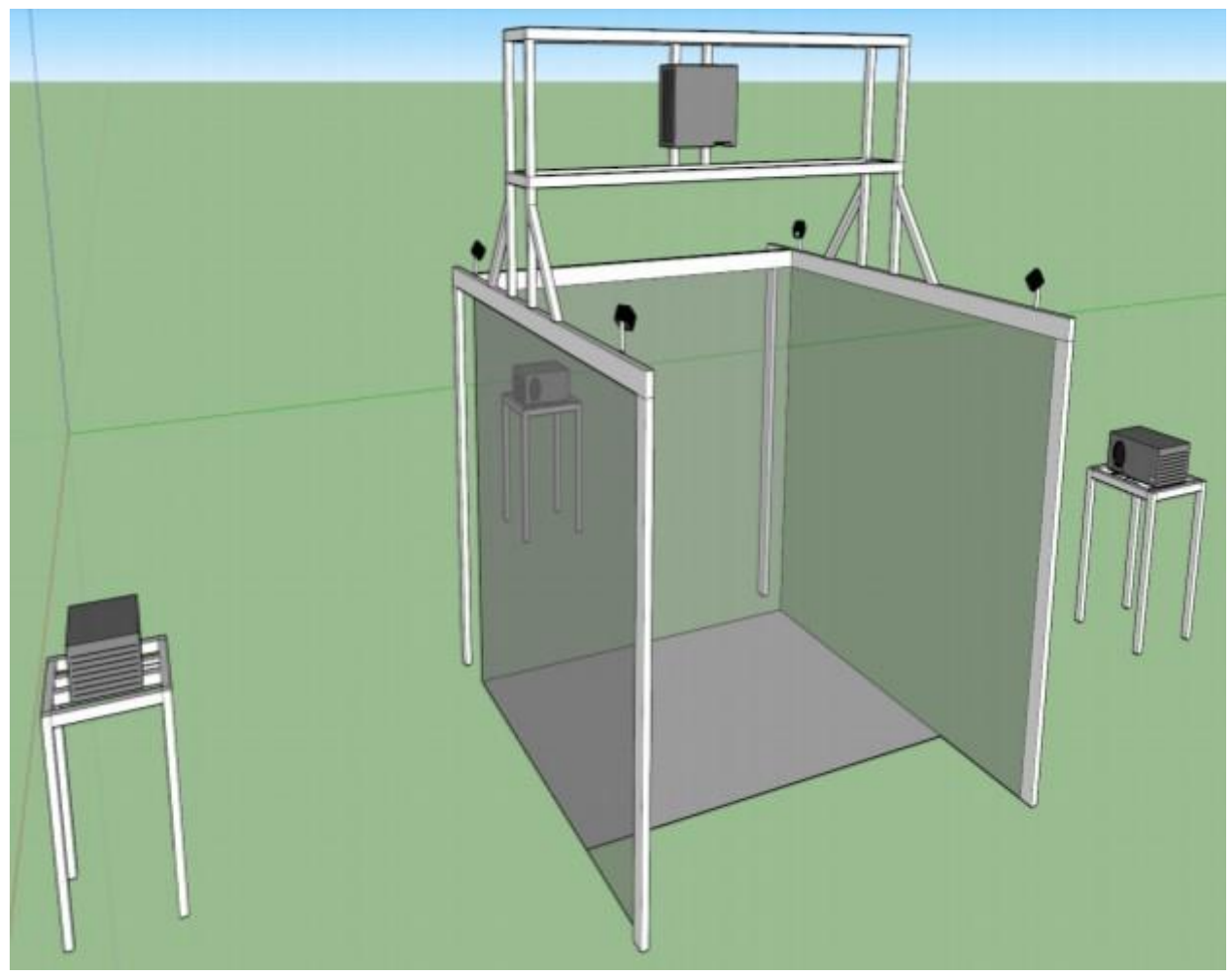

Şekil 1. Dört-Yüzey Konfigürasyonlu CAVE Sistemi.

Önerilen sistemin kurulumu için en az 130m2'lik (12m x 11m) bir alana ihtiyaç duyulmaktadır. Kurulum tasarımında binalardaki taşıyıcı unsur ve kolonların bulunduğu yerler ve kapattığı açılar göz önünde bulundurulmalıdır. Şekil 2'de yansıtım ekipmanlarının yüzeylere ne kadar mesafede yerleştirmesi gerektiği gösterilmektedir. Kullanılması planlanan projeksiyon sistemleri, eğitim ve sinema sektöründe kullanılanların aksine, ters yüzeyden yansıtma yapmaktadır.

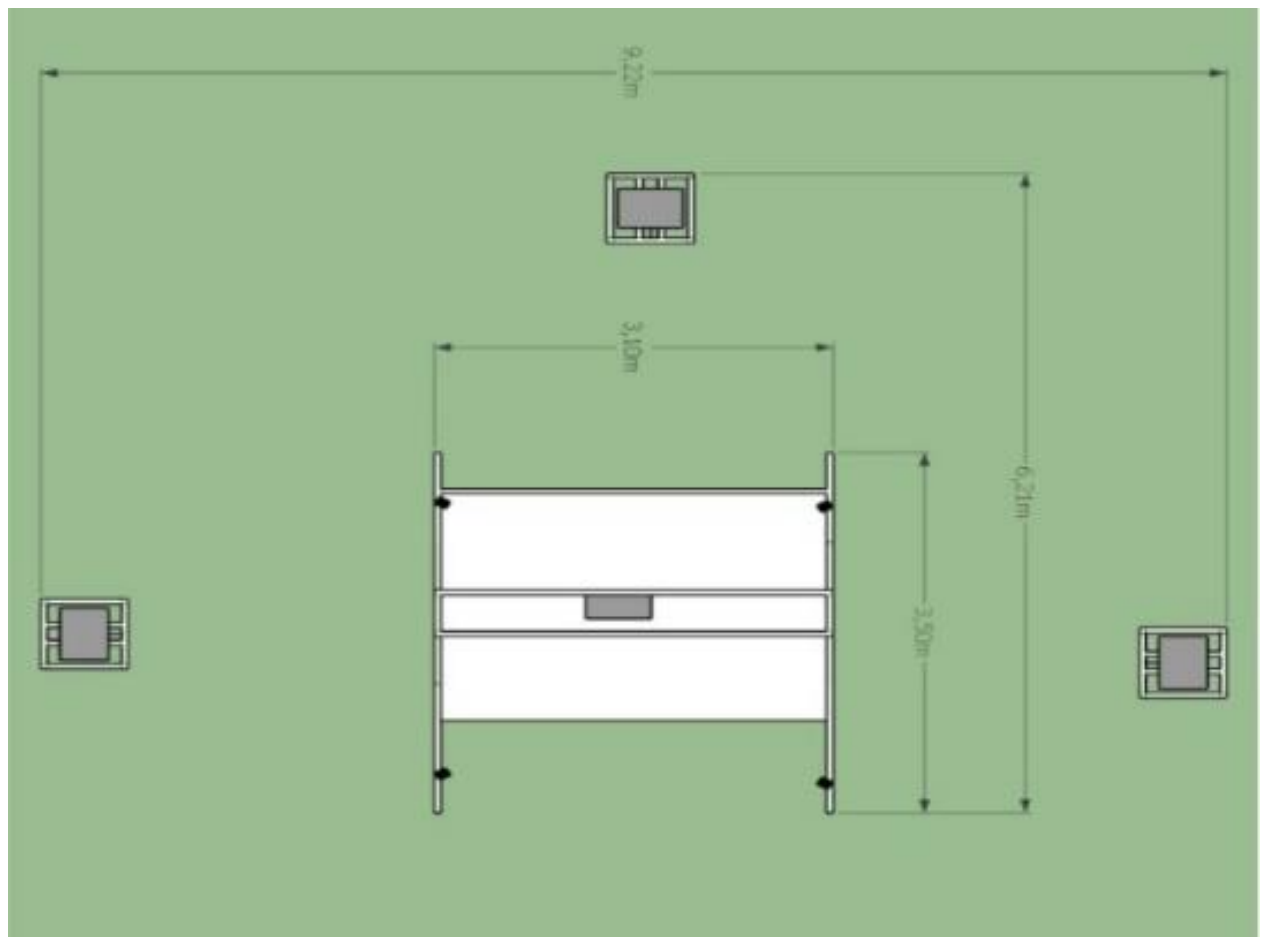

Şekil 2. Kuşbakışı Görünüm.

Kurulum için tercih edilecek alanın en önemli özelliklerinden biri yüksek tavan gereksinimidir. Zemin yüzeyine kullanılacak yansıtıcının en az 3,5 metre yüksekliğe konulması durumu, kurulum tercihinde göz ardı edilmemelidir. Bu mesafe, zemin yüzey alanının büyütülmesi ve kullanılacak yansıtıcı ekipmanın niteliğine göre değişkenlik gösterebilir ve daha yüksek tavan mesafesi gerekebilir. Şekil 3'de örnek durum çalışmasında zemin yansıtıcısının ve takip ekipmanlarının konumlandı̆̆ı yerler gösterilmektedir. 


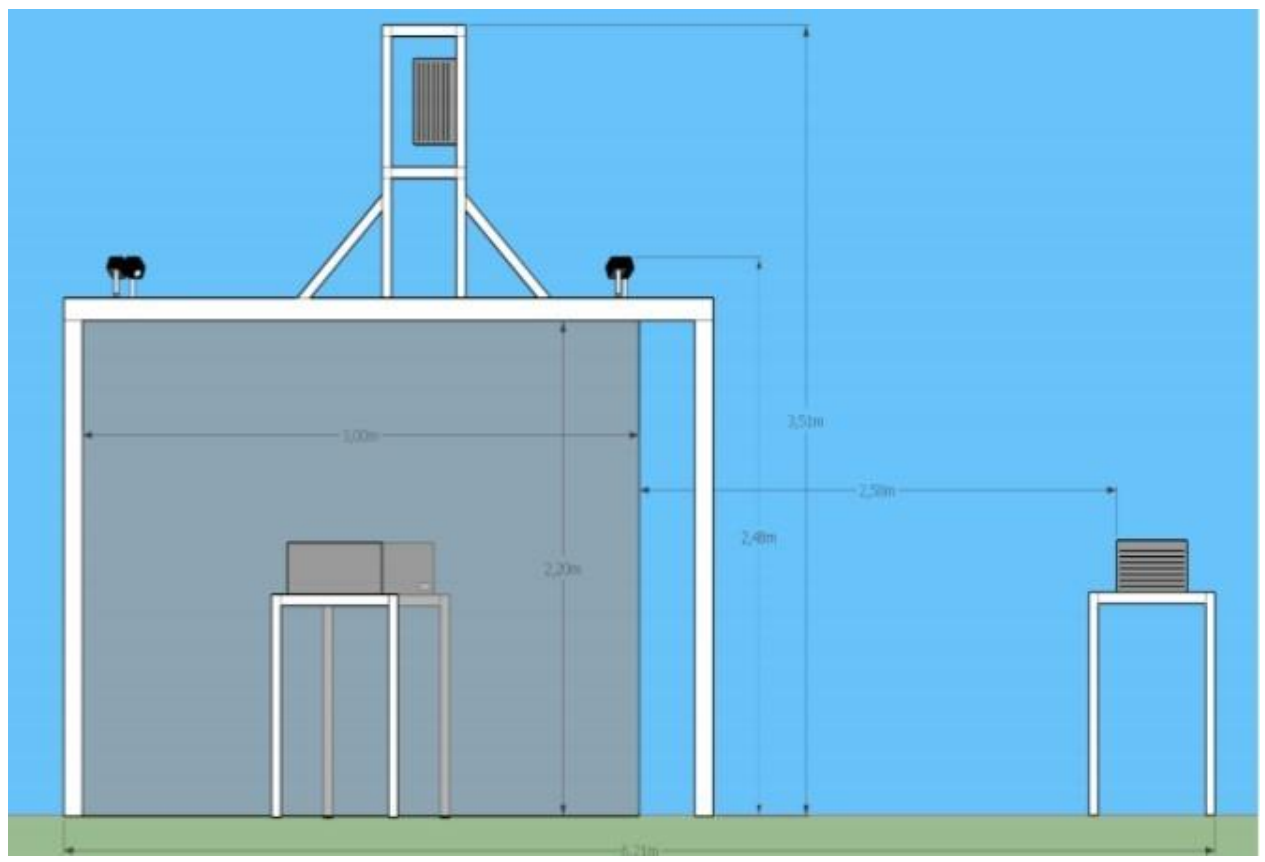

Şekil 3. Zemin Yansıtıcısının ve Takip Ekipmanlarının Görünümü.

Yansıtıcı ekipmanların alternatifi olarak CAVE sistemlerinde ekranların kullanımı da yaygındır. Kurulum maliyeti daha yüksek olan bu yaklaşım, daha fazla sanal gerçeklik hissi vermektedir. Yüksek bütçeli projeler için yansıtıcı yerine büyük ekranların kullanılması alternatifi, alan gereksinimlerini azaltacak ve projeksiyon kullanımından doğan karanlık ve doğrudan güneş almayan yer gereksinimi ihtiyacını ortadan kaldıracaktır.

\section{Sonuçlar}

CAVE sanal gerçeklik teknolojisi klasik sanal gerçeklik teknolojilerinin üzerinde özellikler barındırdığı için sağladığı yararlar üst düzeydedir ancak yüksek yatırım maliyetleri yaygınlaşmasının önündeki büyük engellerden birisidir. Bu tür altyapıları, farklı fonlarla kurmak isteyen üniversiteler ve şirketler için bu çalışmada, örnek durum çalışmasıyla birlikte elde edilecek kazanımlar farklı açılardan kapsamlı olarak tartışılmıştır. Bu konuda henüz bilgi birikimi ülkemizde yeterli seviyede oluşmadığı için bu çalışmanın, ilgili grup ve kişilere katkı sağlayacağı değerlendirilmektedir. Elde edilecek çıktılar tek adımda gerçekleşmeyecek olup zaman içerisinde çok sayıda projenin ve işbirliğinin önünü açacağından, bu kapsamda açılacak merkezlerin ülkemiz açısından önemli kazanımlar sunabileceği tespit edilmiştir. Bu konuda altyapı kurmak üzere proje geliştirmek isteyen firmalar ve üniversiteler için Mantıksal Çerçeve Matrisi hazırlanmış ve ek olarak, maliyet-etkin şekilde bir CAVE sisteminin kurulabilmesi için örnek bir durum çalışmasında gerekli çizimler sunulmuştur. Sanal Gerçeklik teknolojisi, önümüzdeki yıllarda büyüyen bir ivmeyle birçok sektörü etkileyeceği için bu aşamada bu tür teknolojilerin üniversitelerin içerisinde açılması, sektörel işbirliklerinin oluşmasına katkı verecektir. Tüm yatırım maliyetinin paylaşılabilmesi için farklı üniversitelerin bir araya gelerek, maliyetleri ilk aşamada paylaşması ve ardından açılacak olan merkezin paylaşımlı kullanıma açılması da dikkate alınabilecek diğer hususlardan birisidir. Bu alanda çalışan araştırmacıların önünün açılması, projeler üretilerek sanayiye katkı verilebilmesi için bu alanda projeler üretilmesi kaçınılmazdır. Bu alandaki firsatın bu aşamada kaçırılmaması için karar alıcıların stratejik planlamalarında bu alandaki yatırımları dikkate alması gerekmektedir. Fark yaratabilecek projelerin bu tür altyapılarla ortaya çıkarıldığı düşünülürse, ilk başta gerekli olan altyapı yatırımının karşılanabileceği değerlendirilmektedir.

Medikal uygulama alanları, askeri uygulamalar, karmaşık sistemlerin simülatörleri, üretim sektörü, güvenliğe dönük senaryolar, uçuş simülatörleri bu tür bir sistemle ortaya çıkarılabilecek uygulamalardan sadece birkaçıdır. Tek başına bir simülatörün geliştirilme maliyeti dikkate alındığında, CAVE sisteminin bu tür bir simülatöre dönüştürülmesi maliyet etkin olabilmektedir. Sadece simülasyon alanında bile çok sayıda proje bu teknoloji kullanılarak üretilebilmektedir. CAVE sistemlerinin coğrafi olarak farklı yerlerde bulunan kullanıcıları buluşturma ve müşterek çalışmalar gerçekleştirme yönünde iyileştirme çalışmaları devam etmektedir. Yakın gelecekte yapılacak güncellemeler ile konum bağımsız bir şekilde üç boyutlu projelerin ortak yürütülmesi mümkün olacaktır.

CAVE sistemi konusunda tecrübesi bulunmayan ve sadece HMD tip cihazlar üzerinde uygulama geliştirmiş uzmanlar, bu tür sistemlere gerek olmadığını zaman zaman ifade edebilmektedir ancak CAVE sisteminin etkileşimin şeklini değiştiren yönleriyle tanıştıkları anda bu fikirlerinden sıyrılarak CAVE sistemini desteklemeye başlamaktadırlar. Bu çalışmanın yazarları, ilk bakışta mevcut olan zayıf bakış açısının değişimini yakından görmüş oldukları için ilk bakışta gelecek olan tepkilerin, tecrübe eksikliğinden kaynaklandığını değerlendirmekte ve derin kaygısı olan kullanıcılara gerçek bir CAVE sistemiyle tanışmalarını önermektedir. Bu konuda kurulacak merkezlerin ilgili yatırım ajansları tarafından desteklenmesinin kritik öneme sahip olduğu değerlendirilmektedir. 


\section{Kaynakça}

[1] 21. Yüzyılda Mühendislik için 14 Büyük Zorluk. http://engineeringchallenges.org/challenges.aspx/. (Erişim Tarihi: 07.01.2019)

[2] Cruz-Neira, C., Sandin, D. J., DeFanti, T. A., Kenyon, R. V., Hart, J. C. 1992. The cave: audio visual experience automatic virtual environment, Communications of the ACM, cilt. 35, no. 6, s. 64-73. DOI: 10.1145/129888.129892

[3] Febretti, A., Nishimoto, A., Thigpen, T., Talandis, J., Long, L., Pirtle, J., Peterka, T., Verlo, A., Brown, M., Plepys, D. 2013. Cave2: a hybrid reality environment for immersive simulation and information analysis, in The Engineering Reality of Virtual Reality 2013, cilt. 8649, p. 864903, International Society for Optics and Photonics, 2013.

[4] Karkar, A. G., Chowdhury, M. E., Nawaz, N. 2017. Surround-screen mobile based projection: Design and implementation of mobile cave virtual reality, IEEE Access, DOI: 10.1109/ACCESS.2017.2772300

[5] DeFanti, T., Acevedo, D., Ainsworth, R., Brown, M., Cutchin, S., Dawe, G., Doerr, K. U., Johnson, A., Knox, C., Kooima, R. 2011. The future of the cave, Open Engineering, cilt. 1, no. 1, s. 16-37, DOI:https://doi.org/10.2478/s13531-010-0002-5

[6] Infotron elektronik ve bilgisayar sistemleri üretim ve ticaret anonim Şirketi. http://www.infotron.com.tr/ (Erişim Tarihi: 07.01.2019)

[7] Muhanna, M. A. 2015. Virtual reality and the cave: Taxonomy, interaction challenges and research directions, Journal of King Saud University-Computer and Information Sciences, cilt. 27, no. 3, s. 344-361, DOI: https://doi.org/10.1016/j.jksuci.2014.03.023

[8] Ip, H. H., Wong, S. W., Chan, D. F., Byrne, J., Li, C., Yuan, V. S., Lau, K. S., Wong, J. Y. 2018. Enhance emotional and social adaptation skills for children with autism spectrum disorder: A virtual reality enabled approach, Computers \& Education, cilt. 117, s. 1-15, DOI: 10.1016/j.compedu.2017.09.010

[9] Fabrika, M., Valent, P., Scheer, L. 2018. Thinning trainer based on forest-growth model, virtual reality and computer-aided virtual environment, Environmental Modelling \& Software, cilt. 100, s. 11-23, DOI: https://doi.org/10.1016/j.envsoft.2017.11.015

[10] Fernandez, R. P., Alonso, V. 2015. Virtual reality in a shipbuilding environment, Advances in Engineering Software, cilt. 81, s. 30-40.

[11] Limniou, M., Roberts, D., Papadopoulos, N. 2008. Full immersive virtual environment CAVETM in chemistry education, Computers \& Education, cilt. 51, no. 2, s. 584-593, DOI: 10.1016/j.compedu.2007.06.014

[12] Sinitski, E., Thompson, A., Godsell, P. C., Honey, J. L. N., Besemann, M. 2018. Postural stability and simulator sickness after walking on a treadmill in a virtual environment with a curved display, Displays, cilt. 52, DOI: DOI10.1016/j.displa.2018.01.001

[13] Manjrekar, S., Sandilya, S., Bhosale, D., Kanchi, S., Pitkar, A., Gondhalekar, M. 2014. Cave: An emerging immersive technologya review, in Computer Modelling and Simulation (UKSim), 2014 UKSim-AMSS 16th International Conference on, pp. 131-136, IEEE.

[14] Kenyon, R. V. 1995. The cave (tm) automatic virtual environment: Characteristics and applications, Workshop on HumanComputer Interaction and Virtual Environments, s. 150-167.

[15] Jacobson, J. 2003. Using caveut to build immersive displays with the unreal tournament engine and a pc cluster, Proceedings of the 2003 symposium on Interactive 3D graphics, s. 221-222, ACM.

[16] Desai, P. R., Desai, P. N., Ajmera, K. D., Mehta, K. 2014. A review paper on oculus rift-a virtual reality headset, arXiv preprint arXiv:1408.1173.

[17] Evans, G., Miller, J., Pena, M. I., MacAllister, A., Winer, E. 2017. Evaluating the microsoft hololens through an augmented reality assembly application, Degraded Environments: Sensing, Processing, and Display 2017, vol. 10197, s. 101970V, International Society for Optics and Photonics.

[18] Dempsey, P. 2016. The teardown: HTC Vive VR headset, Engineering \& Technology, cilt. 11, no. 7-8, s. 80-81, DOI: 10.1049/et.2016.0731

[19] Brown, A., Green, T. 2016. Virtual reality: Low-cost tools and resources for the classroom, TechTrends, vol. 60, no. 5, s. 517519. DOI: $10.1007 / \mathrm{s} 11528-016-0102-\mathrm{z}$ 